\title{
EMISSION AND COMBUSTION CHARACTERISTICS OF DIFFERENT FUELS IN A HCCI ENGINE
}

\author{
S.Mohanamurugan ${ }^{1,2}$ and S. Sendilvelan ${ }^{1}$ \\ ${ }^{1}$ DR. MGR Educational and Research Institute \\ Maduravoyal, Chennai, India \\ ${ }^{2}$ Department of Mechanical Engineering \\ Velammal Engineering College, Chennai, India \\ Phone: +91 09380590534 \\ E-mail: sivallakshmi@yahoo.co.uk
}

\begin{abstract}
Different intake valve timings and fuel injection amounts were tested in order to identify their effects on exhaust emissions and combustion characteristics using variable valve actuation (VVA) in a Homogeneous Charge Compression Ignition (HCCI) engine. The HCCI engine is a promising concept for future automobile engines and stationary power plants. The two-stage ignition process in a HCCI engine creates advanced ignition and stratified combustion, which makes the ignition timing and combustion rate controllable. Meanwhile, the periphery of the fuel-rich zone leads to fierce burning, which results in slightly high NOx emissions. The experiments were conducted in a modified single cylinder water-cooled diesel engine. In this experiment we use diesel, bio-diesel (Jatropha) and gasoline as the fuel at different mixing ratios. HCCI has advantages in high thermal efficiency and low emissions and could possibly become a promising combustion method in internal combustion engines.
\end{abstract}

Keywords: HCCI, two stage ignition, NOx, bio-diesel, variable valve actuation

\section{INTRODUCTION}

In modern society the internal combustion engine is the key to the entire transportation sector. Without the transportation performed by millions of vehicles on the roads and at sea we would not have reached the living standard we enjoy today. Spark ignition, SI, and compression ignition, CI, are the two types of internal combustion engines (Gray and Ryan, 1997). Petrol and diesel are at present the principal fuels for SI and CI engines. These fuels are on the verge of becoming extinct and during combustion they release substantial amounts of pollutants into the atmosphere, creating environmentalrelated problems. The internal combustion engine is known as one of the major sources of air pollutants in the environment. The fuel oxidation process in the engine generates not only useful power, but also a considerable amount of pollutant emissions including carbon dioxide $\left(\mathrm{CO}_{2}\right)$, carbon monoxide $(\mathrm{CO})$, unburned hydrocarbon $(\mathrm{HC})$, nitrogen oxides (NOx), and particulate matter. Reducing exhaust emissions and increasing the fuel economy of internal combustion engines are of global importance. $\mathrm{CO}_{2}$ is mainly responsible for the global warming issue as it creates a reflective layer in the atmosphere that reflects heat from the earth back to the earth's surface, increasing the earth's average temperature over time. Carbon monoxide $(\mathrm{CO})$ is a very dangerous substance since it reduces the oxygen-carrying capacity of the blood stream. At low 
concentrations, $\mathrm{CO}$ inhalation can cause dizziness and nausea, while at higher concentrations it can be deadly (Kim and Lee, 2006). Unburned hydrocarbon emission, a result of an incomplete combustion process, is a common source of respiratory problems. Particulate emissions or soot also cause some respiratory problems. Both unburned hydrocarbon and soot emissions have been linked to some cancers in several studies. The high flame temperature generated during the combustion process is responsible for NOx formation, which causes various health problems as well as contributing to acid rain and global warming issues (Zhao et al., 2003).

The development of efficient internal combustion engines with ultra low emissions is necessitated by strict regulations on exhaust gas composition and fuel economy. Increasing concern over the potential global warming effects of major greenhouse gases from current fossil fuels, coupled with a rapidly growing vehicle fleet around the world, has intensified the uptake of alternative fuels and become an important area of research (Yap et al., 2005). Bio diesel is capable of solving the problems of fuel supply in a decentralized fashion and can simultaneously help to reduce environmental-related problems (Yeom et al., 2006). Jatroba oil has been recognized as a major source to replace the declining fuel resources and could be used in IC engines. Carbon dioxide is one of the major greenhouse gases. Although the burning of biodiesel produces carbon dioxide emissions similar to those from ordinary fossil fuels, the plant feedstock used in the production absorbs carbon dioxide from the atmosphere when it grows. Plants absorb carbon dioxide through a process known as photosynthesis which allows them to store energy from sunlight in the form of sugars and starches (Shi et al., 2006). After the biomass is converted into bio diesel and burnt as fuel the energy and carbon is released again. Some of that energy can be used to power an engine, while the carbon dioxide is released back into the atmosphere.

In parallel to this interest in alternative fuels, there has also been increased interest in Homogenous Charge Compression Ignition (HCCI) combustion. HCCI technology, incorporating the advantages of both spark ignition and compression ignition, is a potential candidate for future ultralow-emission engine strategies (Jiang et al., 2005). HCCI engines are being actively developed because they have the potential to be highly efficient and to produce low emissions (Standing et al., 2005). HCCI engines can have efficiencies close to those of diesel engines, with low levels of emissions of oxides of nitrogen (NOx) and particulate matter (PM). In addition, HCCI engines have been shown to operate with a range of fuels, e.g. natural gas, gasoline and bioethanol (Babajimopoulos et al., 2002).

\section{EXPERIMENTAL SETUP}

In this study, an electrical dynamometer is assembled on a four-cylinder engine as shown in Figure 1. A four-stroke indirect injection diesel engine was used. There are different thermo junctions and electrical units on the dynamometer and the engine. Circuits in all units were connected to each other, and they were controlled by a computer. In addition, two exhaust emission measurement systems worked independently to ascertain the levels of $\mathrm{HC}, \mathrm{CO}, \mathrm{CO}_{2}$, and $\mathrm{NOx}$ respectively. In addition, an adjustment tool was used to adjust the injection pressure. 


\section{Engine Specifications:}

$\begin{array}{lll}\text { Bore } \mathrm{x} \text { Stroke } & = & 80 \times 110 \mathrm{~mm} \\ \text { Cubic Capacity } & = & 0.553 \mathrm{lit} \\ \text { Compression Ratio } & = & 16.5: 1 \\ \text { Engine Wt. (dry) w/o flywheel } & = & 114 \mathrm{~kg} \\ \text { Weight of flywheel } & = & 33 \mathrm{~kg}\end{array}$

Exhaust gas can be very hot if retained or re-inducted from the previous combustion cycle or cool if re-circulated through the intake as in conventional Exhaust Gas Recirculation (EGR) systems. The exhaust has dual effects on HCCI combustion. It dilutes the fresh charge, delaying ignition and reducing the chemical energy and engine work. Hot combustion products conversely will increase the temperature of the gases in the cylinder and advance ignition.

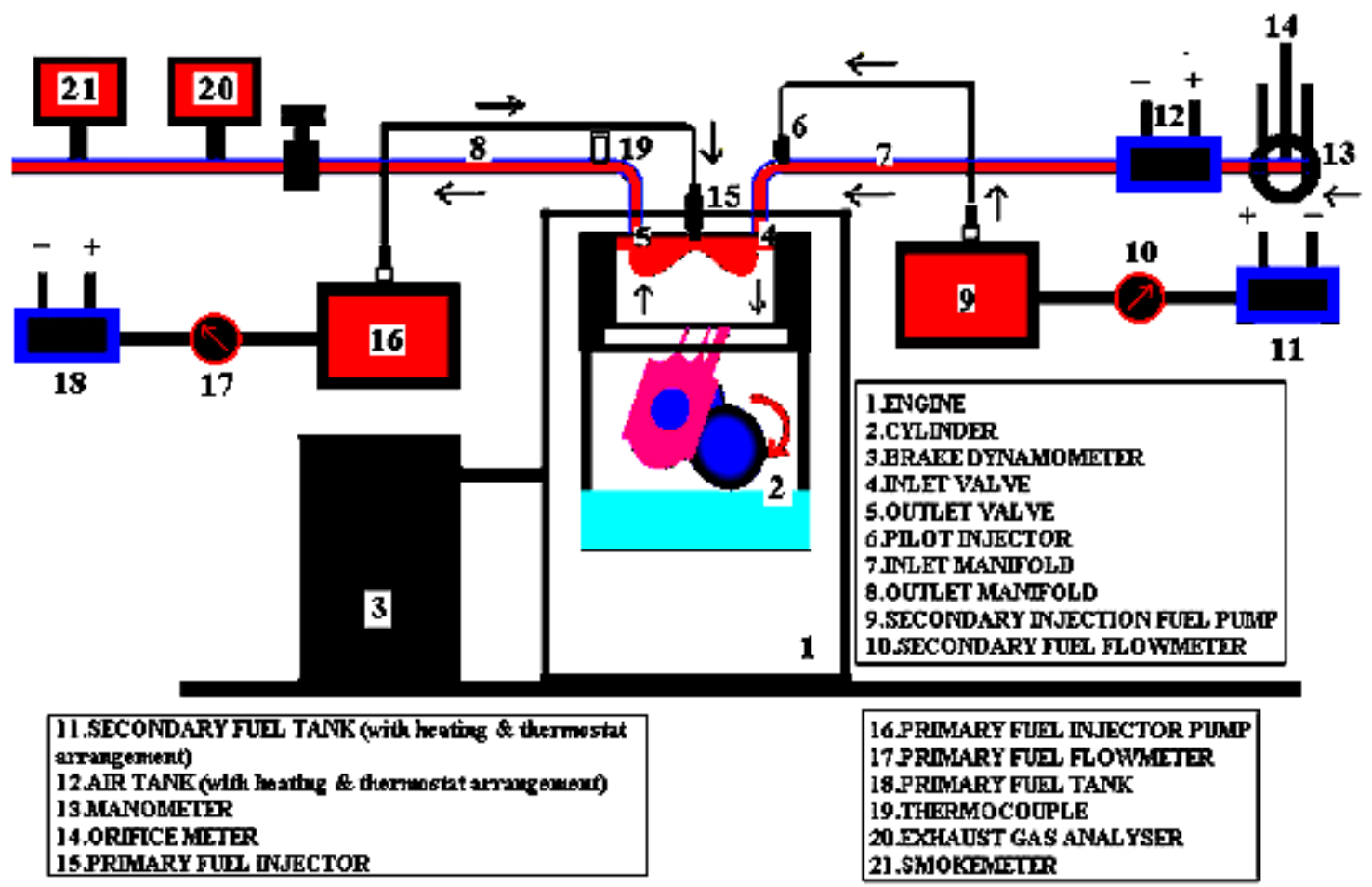

Figure 1. Picture of the experimental setup

\section{WORKING PRINCIPLE}

In this experiment we analyse the performance and emission characteristics using premixed charge compression ignition (PCCI) mode assisted with a secondary pilot injector as combustion initiator in a HCCI engine. The fuel is heated by means of a $1000 \mathrm{~W}$ water bath provided with an electrical thermostat, which enabled us to maintain the fuel at the desired temperature. The maximum fuel temperature that can be achieved using our setup is $75^{\circ} \mathrm{C}$. In the case of diesel we maintained the temperature at $55^{\circ} \mathrm{C}$, and in the case of bio-diesel we maintained the temperature at $75^{\circ} \mathrm{C}$. The air is heated by means of an $800 \mathrm{~W}$ air heater placed in the inlet manifold. The air temperature is maintained by means of an electrical thermostat to a maximum of about $80^{\circ} \mathrm{C}$. The temperature history of the hottest (and close to adiabatic) portion of the core of the 
experiment is reproduced by the hottest zone. This part of the charge should be the first ignition site.

The fuel is injected into the manifold using an electronic fuel pump through a secondary fuel injector mounted on the inlet manifold whose spray angle is 30 degrees and the fuel line pressure is maintained at 6 bars. The current rating of the fuel injection pump that we have used is $20 \mathrm{~A}$ and that of the fuel injector is $0.3 \mathrm{~A}$. The injection is controlled by an electronic circuit having a limit switch with a frequency of about 750 cycles per minute. The limit switch is actuated by means of a bolt attached to the inlet valve rocker; we have effectively utilized the $8 \mathrm{~mm}$ travel of the rocker arm to generate the electrical signal for initiating the injection during the suction stroke.

In its original form, the HCCI uses a premixed air fuel mixture. This may be achieved through a port fuel injection. In place of this, very early direct injection has also been used. Early direct injection in the combustion chamber, during the intake stroke or early part of the compression stroke, allows better fuel air mixing than a standard diesel combustion scenario. Direct injection also allows stratification of the in cylinder charge, and this offers means to realize stable and efficient combustion during transition from higher to lower engine load. It has been shown that for pure HCCI conditions where a completely pre-mixed charge is used, fuel chemistry and gas mixture temperature are the two major factors that determine the auto ignition process. Mixing and turbulence have a much lesser impact on the auto ignition. However, for "HCCIlike" conditions such as direct injection, where a non-homogeneous charge may be formed, the amount and rate of fuel air mixing may have an impact on the ignition delay and start of combustion. The impact of the initial (i.e. at the end of the fuel injection or start of ignition dwell) temperature and fuel air distribution on ignition dwell was investigated. Various methods to prolong the ignition dwell were used, including variations in injection timing, EGR percentage, engine valve actuation and swirl ratio.

In relation to the HCCI engine is combustion phase control. Hot residual gas supplies heat to the combustion chamber and promotes HCCI combustion. This hot residual gas can be controlled by a variable valve timing (VVT) device. Moreover, the VVT device can improve volumetric efficiency by varying the intake valve's open and close timing.

\section{Injection Timing}

Circumference of the flywheel : : $126.5 \mathrm{~cm}$

Radius of the flywheel : $20.13 \mathrm{~cm}$

The experiment is conducted with different fuels at different mixing ratios at the primary and secondary injectors; the order of fuel injection is as follows.

Mode 1: Diesel conventional

In this mode the experiments are conducted with only primary injection. The diesel is only used as a fuel for combustion. The pilot injector is closed in this mode; there is no fuel supply through the pilot injector. This experiment measures the emissions and fuel consumption with a conventional mode, with preheating of the air before supplying the air into the combustion chamber.

Mode 2: Bio-diesel conventional

In this mode bio-diesel (Jatroba oil) is used as a fuel instead of diesel. 
Mode 3: Diesel PCCI-DI combustion

In this mode of experiments both primary injector and pilot injector are used to supply the fuel into the combustion chamber. Diesel is used as a fuel in both the injectors. The pilot injector supplies the diesel into the combustion chamber before the actual injection of the diesel into the combustion chamber through the primary injection port. The emissions and fuel consumptions are measured in this mode. The PCCI was created by supplying the fuel through the pilot injector after the piston reached the bottom dead centre.

The procedure followed in mode three was also followed for the other modes of experiments given below.

Mode 4: Bio-diesel Bio-diesel PCCI-DI combustion

Mode 5: Diesel Bio-diesel PCCI-DI Combustion

Mode 6 : Bio-diesel Diesel PCCI-DI combustion

Mode 7: Diesel Petrol PCCI-DI combustion

Mode 8: Bio-diesel Petrol PCCI-DI combustion

The suction stroke duration is for $219^{\circ}$

The exhaust stroke duration is for $219^{\circ}$

The inlet valve opens $4.5^{\circ}$ before TDC during the exhaust stroke

The inlet valve closes $34.5^{\circ}$ after BDC during the compression stroke

The exhaust valve opens $34.5^{\circ}$ after BDC during the expansion stroke The exhaust valve closes $4.5^{\circ}$ after TDC during the exhaust stroke

The manifold injection starts $61.239^{\circ}$ after TDC during the suction stroke The manifold injection closes $51.239^{\circ}$ before BDC during the suction stroke The injection duration is for $87.52^{\circ}$ during the suction stroke, for about $2 / 5$ of the suction stroke.

The injection rate is maintained at $7.2 \mathrm{ml} / \mathrm{min}$ during the injection duration.

\section{RESULTS AND DISCUSSION}

\section{Effect of Load on Exhaust Gas Temperature}

The effect of load on the exhaust gas temperature is measured by a thermocouple attached to the outlet manifold. The variation of temperature with the increase of load for all the cases is measured. Figure 2 shows the variation of temperature with increase of load for the conventional mode with diesel, bio diesel, and for HCCI with the Diesel: Diesel and Biodiesel: Biodiesel mode.

The exhaust gas temperature increases with the increase of load in all the cases. This could be due to a greater amount of fuel combustion inside the combustion chamber at higher load, compared to lower load and complete combustion of the fuel. Within the four modes the exhaust gas temperature from conventional diesel mode is higher than the other modes, and the Biodiesel: Biodiesel mode is lower than the other 
modes for all the load conditions (Shi et al., 2006). Compared to conventional modes with diesel and biodiesel modes, the diesel and biodiesel with HCCI modes produced a lower temperature. For the maximum load conditions, the exhaust gas temperatures from the diesel, bio diesel, Diesel: Diesel, Biodiesel: Biodiesel are 315, 306, 278 and $270^{\circ} \mathrm{C}$ respectively.

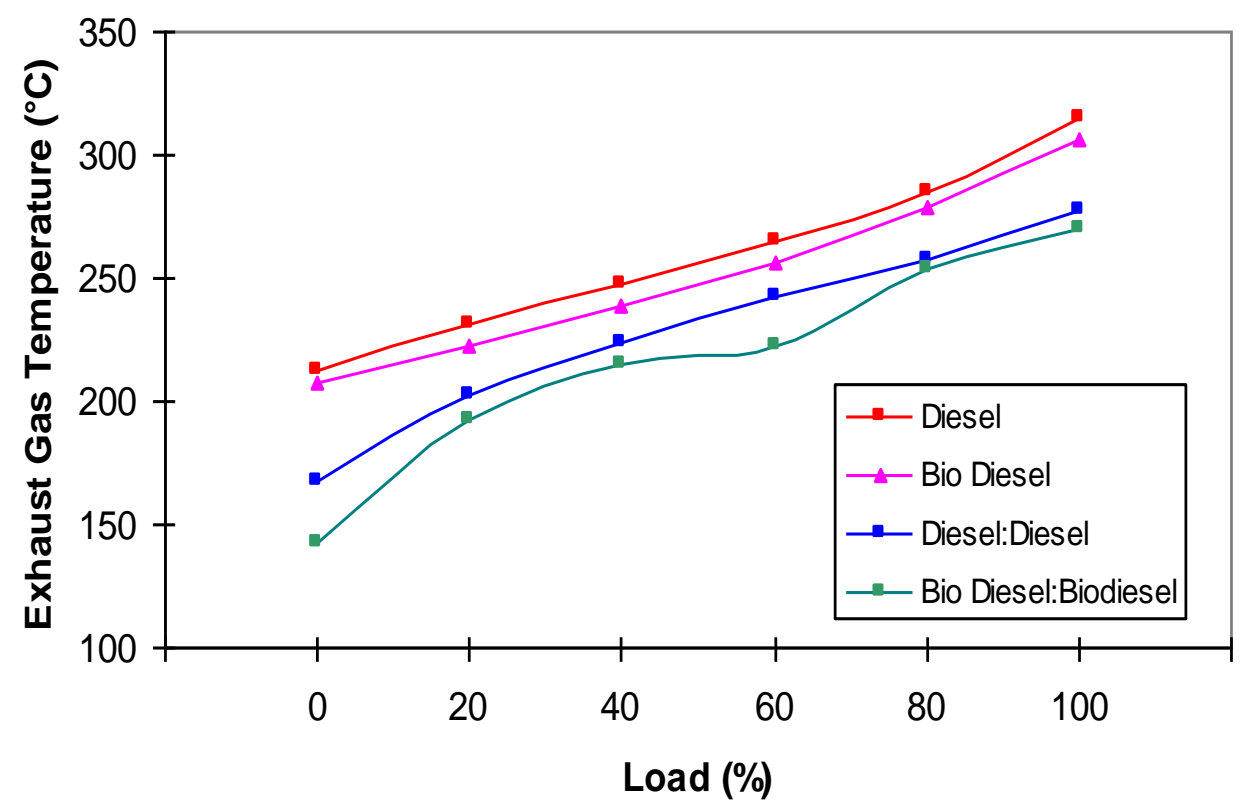

Figure 2. Comparison between conventional and HCCI methods

Figure 3 shows the variations of exhaust gas temperature with the increase of load for the HCCI mode with different primary and secondary fuel supply. Among these, the biodiesel and petrol used with primary and secondary fuels produced lower exhaust gas temperature compared to the other three cases (Diesel: Biodiesel, Biodiesel: Diesel, Diesel: Petrol). The HCCI with different primary and secondary fuels produced lower exhaust gas temperature compared to both the conventional mode and the HCCI mode with the same primary and secondary fuels.

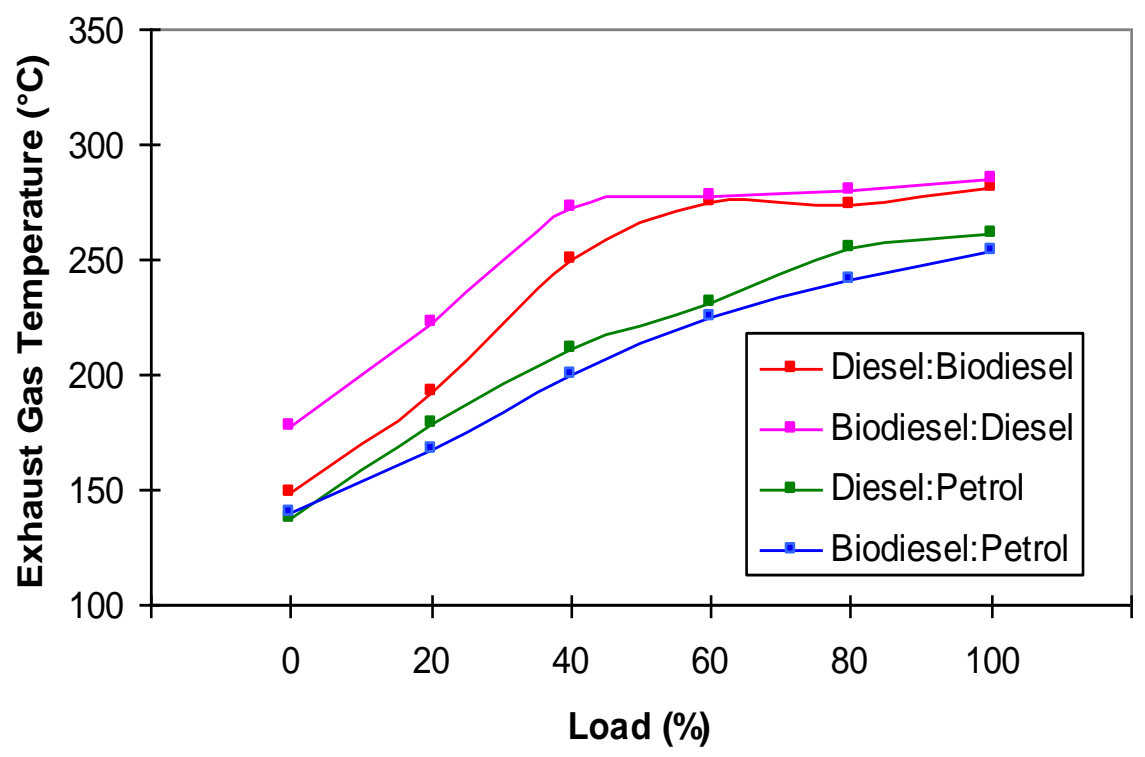

Figure 3. Comparison between different fuels in HCCI mode 


\section{Effect of Load on Hydrocarbon in Exhaust Gas}

The hydrocarbon emission from all the modes is observed with different load conditions. Figure 4 represents the variation of $\mathrm{HC}$ emission with the increase of load from $0 \%$ to $100 \%$. The study found that the $\mathrm{HC}$ emission from conventional diesel mode is higher than the other modes and also that the HC emission from HCCI mode is lower than the conventional mode. The HC emission increased with the increase of load in the conventional mode and decreased with the increase of load in the HCCI mode. Within the HCCI modes, the HC emission from the BD:BD mode is observed as lower than the D:D mode for all the load conditions. In the conventional mode, the HC emission increased from $55 \mathrm{ppm}$ to $108 \mathrm{ppm}$ when the load increased from $0 \%$ to $100 \%$. For the same load interval for BD:BD, the HS emission is observed to decrease from 24 ppm to $11 \mathrm{ppm}$. Figure 5 shows the variation of $\mathrm{HC}$ emission with the increase of load in HCCI mode with different primary and secondary fuels. For all the cases of HCCI mode, the HC emission decreased with the increase of load. Among all the HCCI modes, D:BD produced lower HC emissions and BD:D mode produced higher HC emissions (Kim \& Lee, 2006).

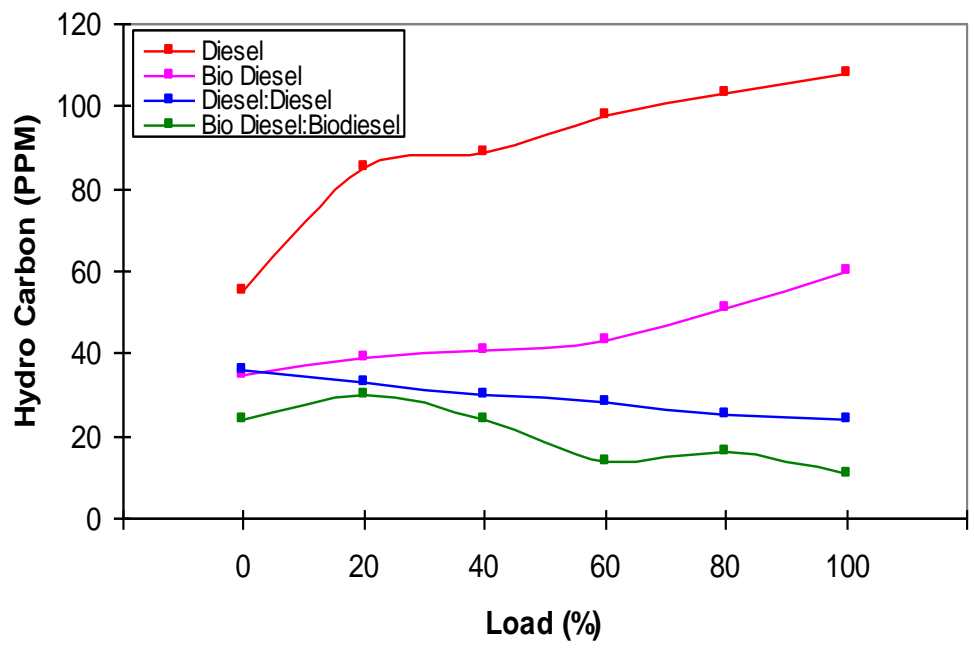

Figure 4. Comparison of hydrocarbon emission between conventional and HCCI methods.

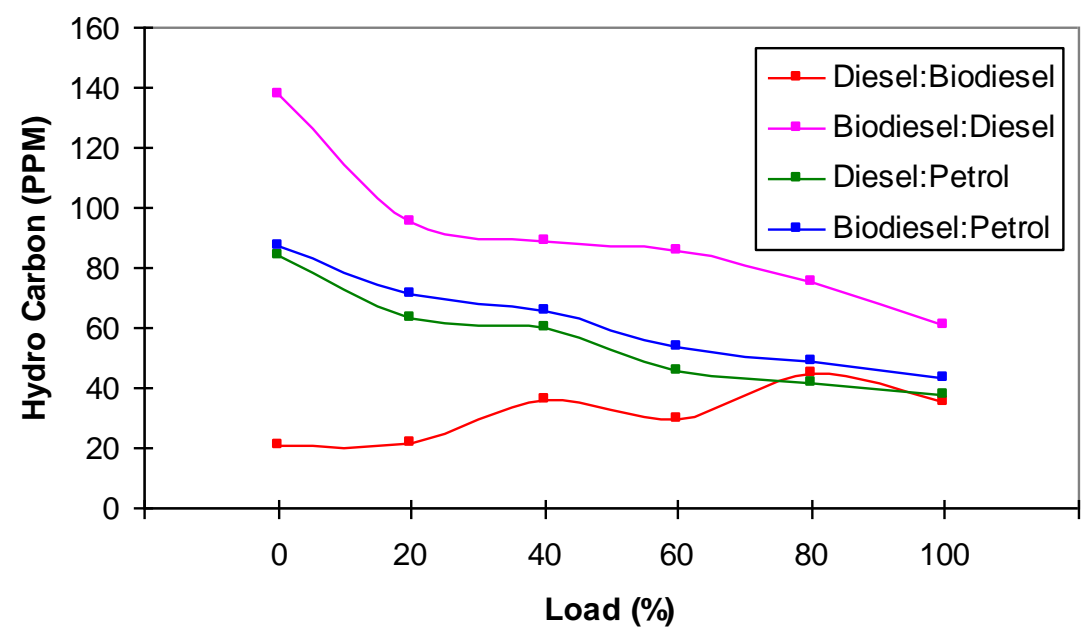

Figure 5. Comparison of hydrocarbon emission between different fuels in HCCI mode. 


\section{Effect of Load on NOx Emission in Exhaust Gas}

The NOx emission is measured in all the modes of the operations in this study. Figure 6 shows the NOx emission from the conventional mode with diesel and bio diesel, and from HCCI with the same fuel for both the primary and secondary injections. In conventional mode, lower NOx emission is observed for the bio diesel-based experiment for all the load conditions compared to diesel-based operations. The HCCI mode operations produced lower NOx emissions than the conventional mode of operations, which could be due to lower and uniform temperature inside the combustion chamber during the combustion process due to uniform mixing of the fuel with air inside the combustion chamber. The engine is also operated in HCCI mode with different fuel as a primary and secondary fuel. The NOx emissions shows that the Biodiesel:Petrol and Diesel:Petrol combinations generate very low NOx emission compared to the other cases of the HCCI mode of operations. The NOx emissions are observed as more or less the same value for these two cases for all the load conditions (Yap et al., 2005). The NOx emission increased from 15 to $330 \mathrm{ppm}$ and 19 to $342 \mathrm{ppm}$ for the Diesel:Petrol and Biodiesel:Petrol modes respectively when the load was increased from 0 to $100 \%$ (Figure 7).

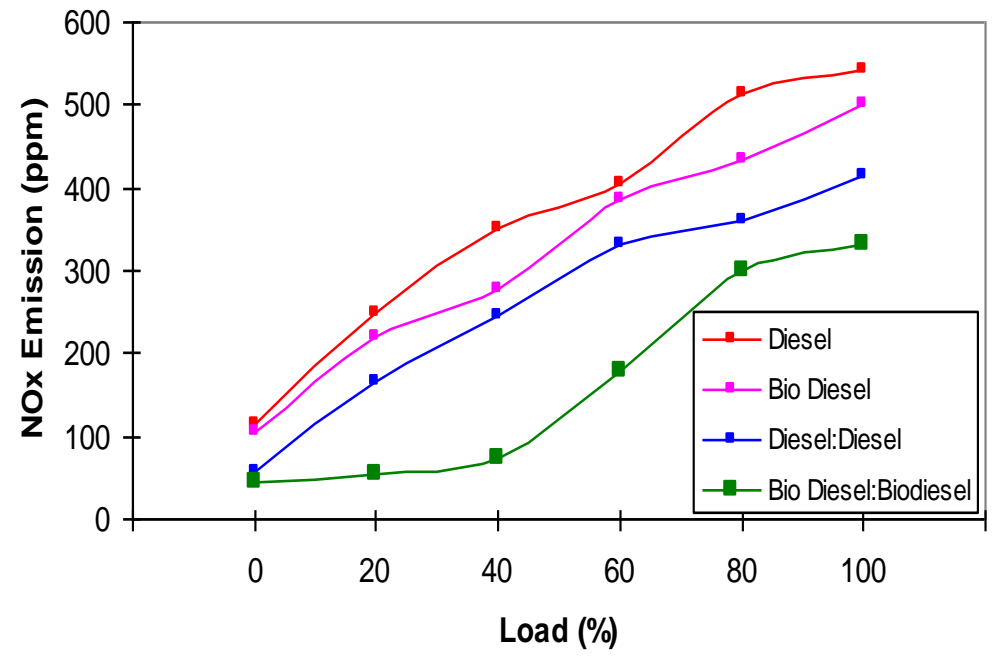

Figure 6. Comparison of NOx emission between conventional and HCCI methods

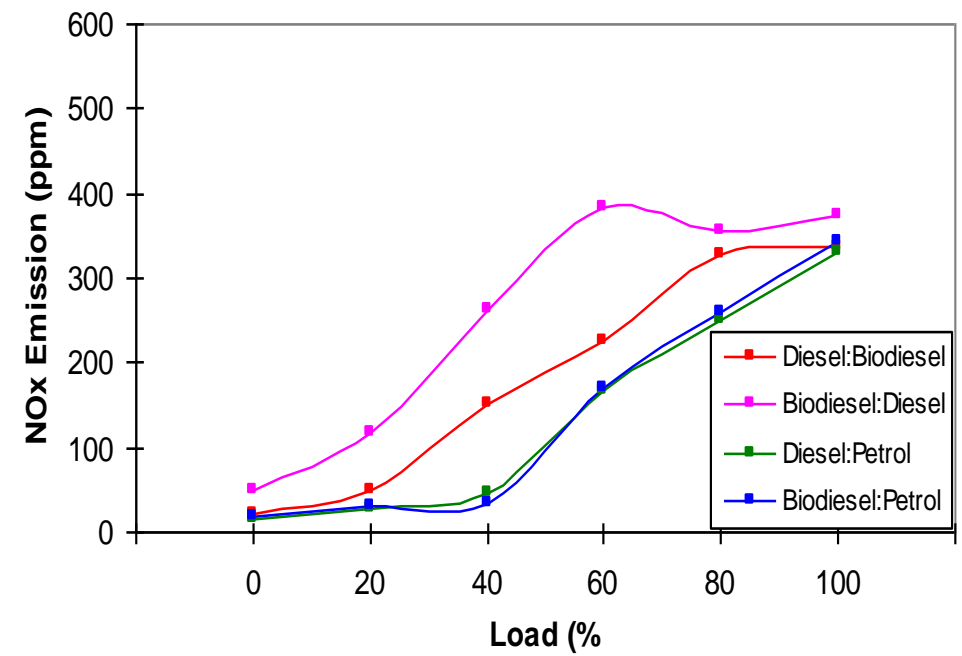

Figure 7. Comparison of NOx emissions between different fuels in HCCI mode 


\section{Effect of Load on Specific Fuel Consumption}

The specific fuel consumption decreased with the increase of load for all the modes of operation (both conventional and HCCI mode).The SFC value is found to be lower in conventional mode than in HCCI mode for all the load conditions. This could be due to the secondary fuel supply in the case of HCCI mode operation compared to the conventional mode in which only primary fuel is supplied. Figure 8 shows the specific fuel consumption with the increase of load for conventional and HCCI modes with the same type of fuel. The study also found that in higher load conditions the specific fuel consumption was the same value for all the cases.

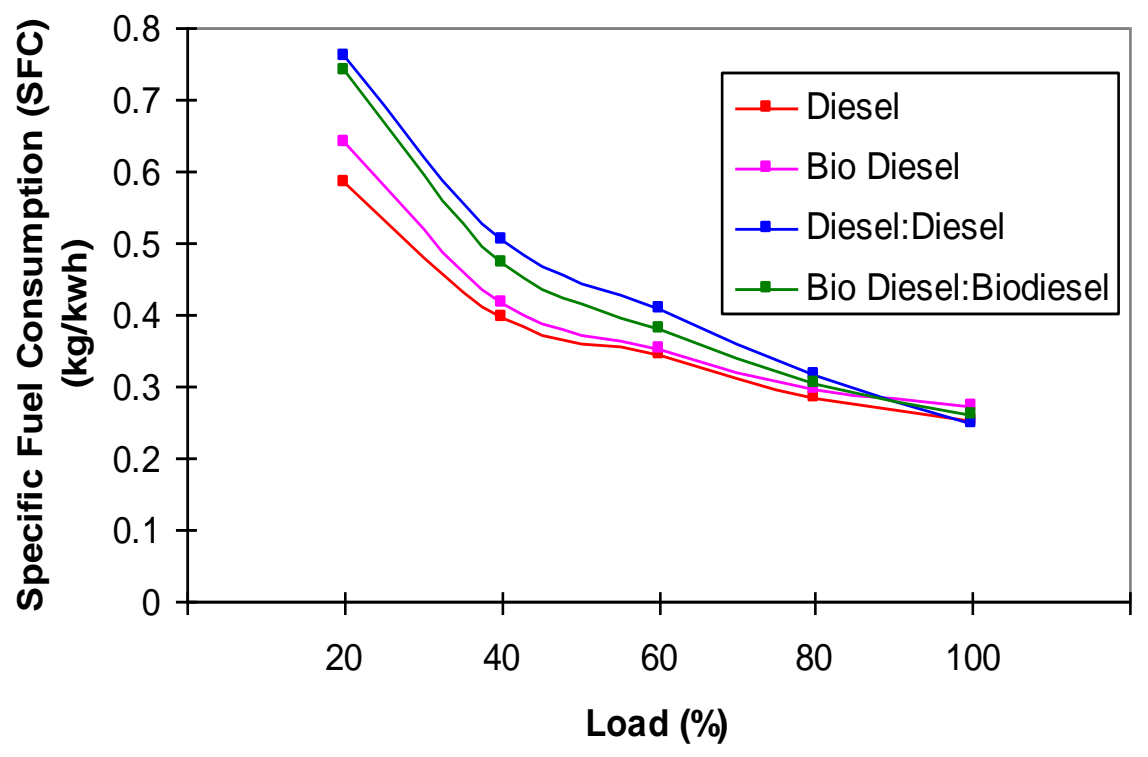

Figure 8. Comparison of specific fuel consumption between conventional and HCCI methods

\section{Effect of Load on Brake Thermal Efficiency}

Variation in the brake thermal efficiency with the variation of fuel in the conventional diesel engine is identified when using diesel and bio-diesel as a fuel in a conventional mode, and using Diesel: Diesel or Bio-diesel: Bio-diesel as a fuel in the HCCI mode with the same fuel for primary and secondary injection. The brake thermal efficiency is measured with an increase from $20 \%$ to $100 \%$ of the load condition, at intervals of $20 \%$ of load. Figures 9 and 10 indicate the variation in the brake thermal efficiency with the increase of load (Yap et al., 2005). 


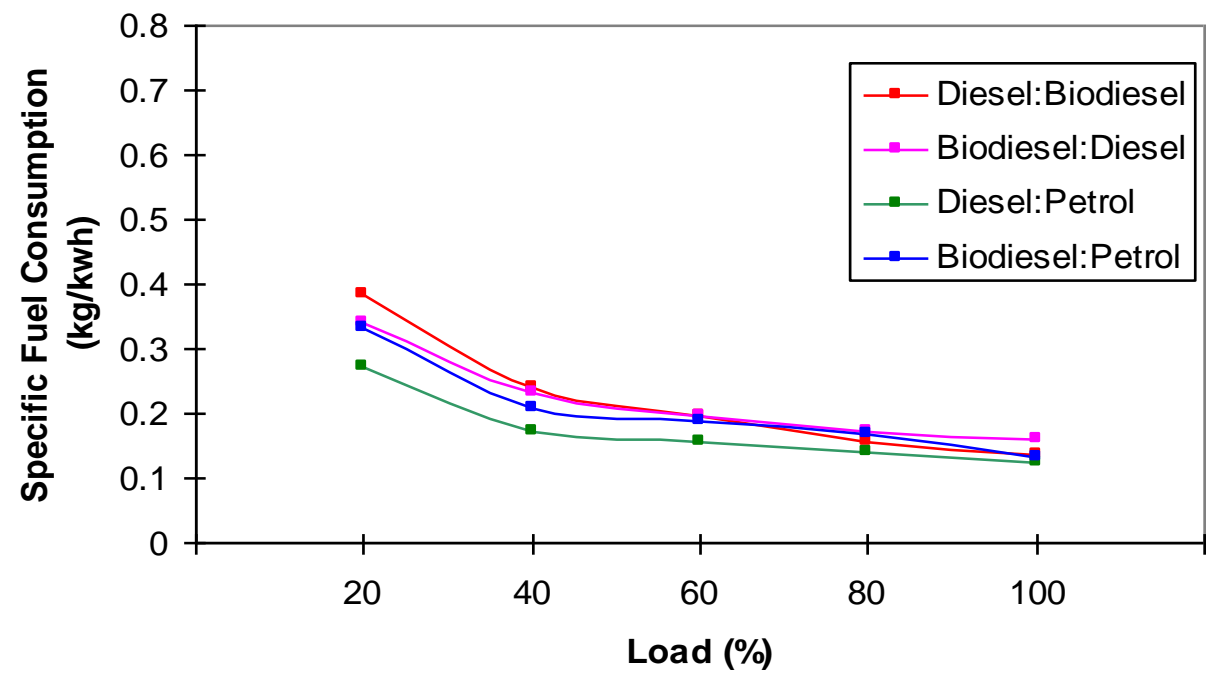

Figure 9. Comparison of specific fuel consumption between different fuels in HCCI mode

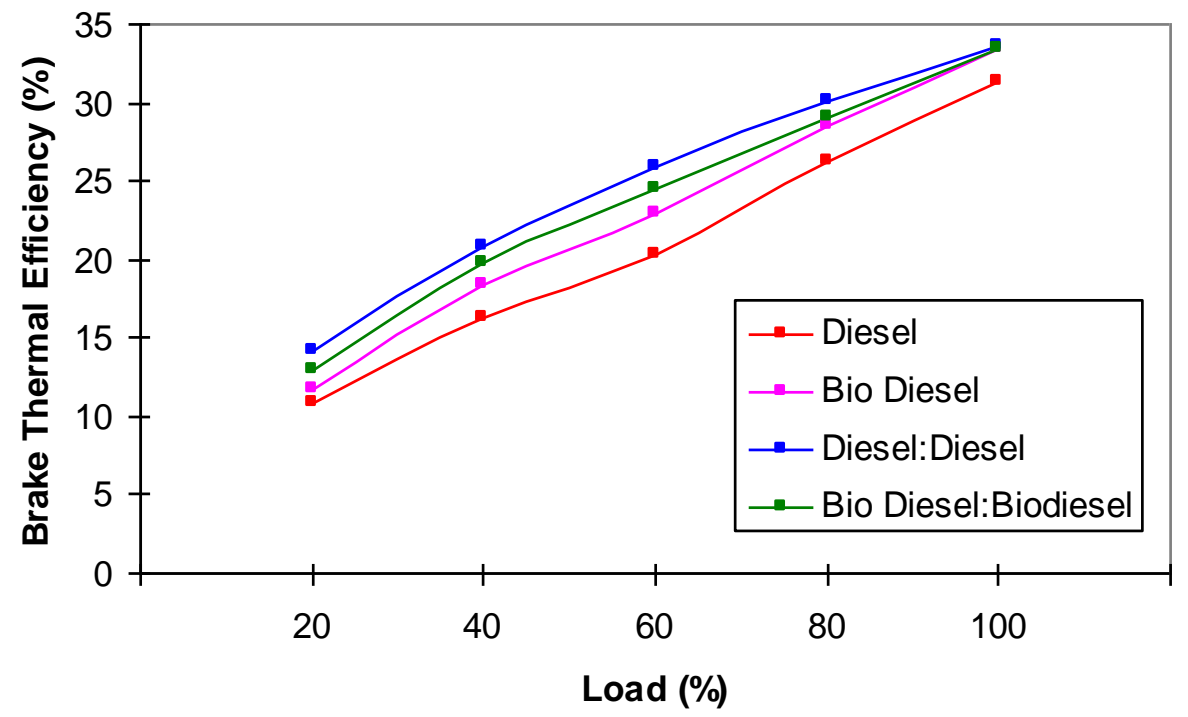

Figure 10. Comparison of brake thermal efficiency between conventional and HCCI methods

The study found that for all the modes of operation the brake thermal efficiency increases with the increase of load. In the case of diesel and bio diesel in the conventional mode of operation, the brake thermal efficiency increased from 10.9 to $31.26 \%$ and 11.75 to $33.39 \%$ respectively when the load increased from $20 \%$ to $100 \%$. For the same fuels, the HCCI mode of operation produced higher thermal efficiency than the conventional mode, which could be due to a lower combustion temperature and complete conversion of the energy available in the fuel into useful form in the case of the HCCI mode of operation compared to the conventional mode. The brake thermal efficiency with different fuels as primary and secondary fuel in the HCCI mode is represented in Figure 11. 


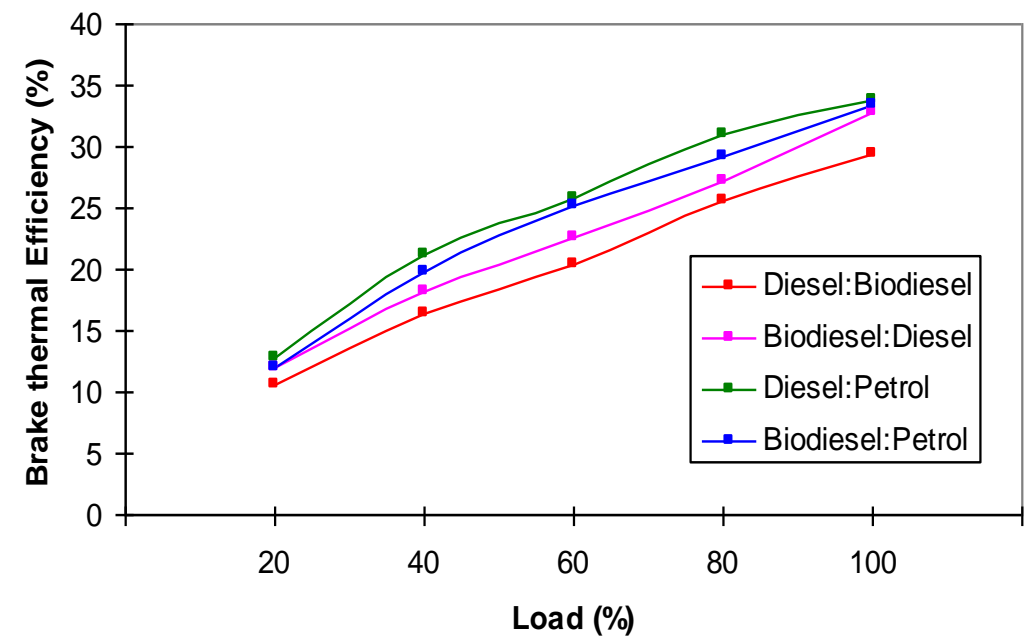

Figure 11. Comparison of brake thermal efficiency between different fuels in HCCI mode

In the case of HCCI with different fuels as primary and secondary fuel supply, diesel and petrol used as primary and secondary fuel produced higher brake thermal efficiency than other modes of operation. Diesel as a primary fuel and biodiesel as a secondary fuel produced lower brake thermal efficiency. The magnitudes of brake thermal efficiency with all the load conditions for different modes of operation are presented in Figure 12. The study identified that, for all load conditions, the Diesel: Diesel and Diesel: Petrol combinations in the HCCI mode of operation produced the maximum thermal efficiency. Lower thermal efficiency is observed for the Diesel conventional and Diesel: Biodiesel HCCI modes.

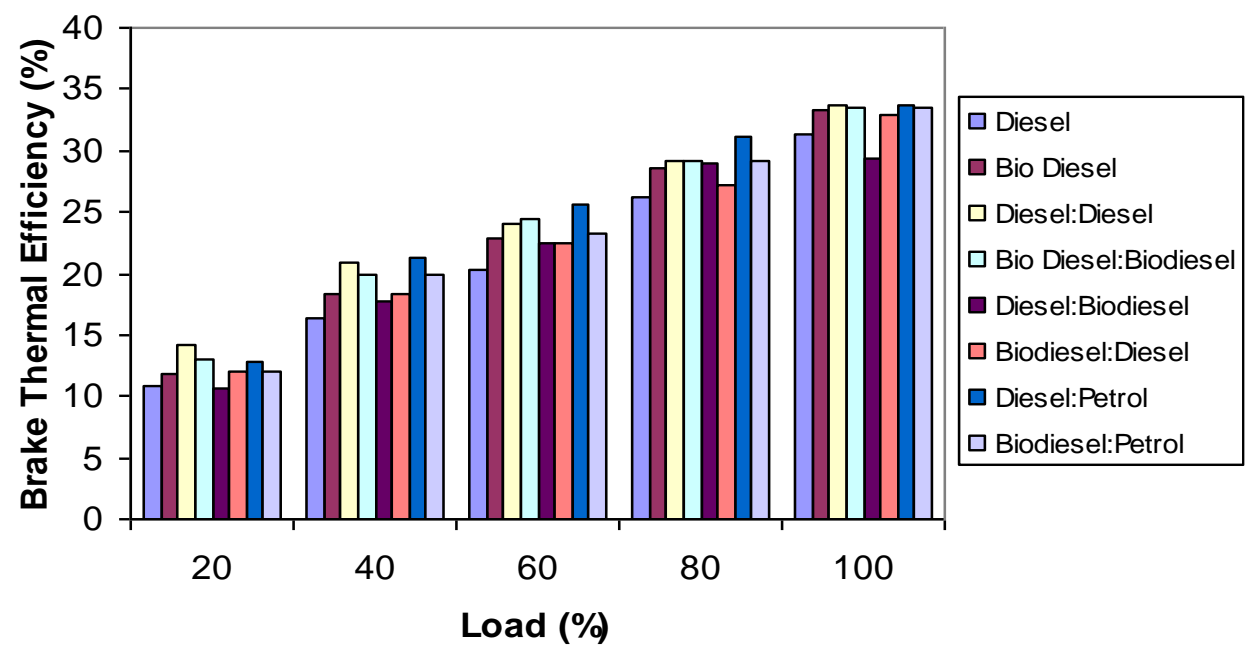

Figure 12. Brake thermal efficiency with different load conditions for all modes of operation

\section{Effect of Load on Carbon Dioxide}

The effect of load on the $\mathrm{CO}_{2}$ emission with the conventional mode and HCCI with the same type of fuel is shown in Figure 13 and 14. The study found that $\mathrm{CO}_{2}$ emission 
from diesel in both conventional and HCCI modes is higher than from biodiesel in the conventional and HCCI modes. This could be due to the variation of the chemical characteristics of the diesel with bio diesel. The $\mathrm{CO}_{2}$ increased from 3 to $6.3 \%$ and 2.5 to $4.9 \%$ for diesel and biodiesel respectively when the load increased from $0 \%$ to $100 \%$. For the same load conditions, the $\mathrm{CO}_{2}$ emission is observed at 2.7 to $5.7 \%$ and 1.8 to $4.8 \%$ respectively for diesel and biodiesel in the HCCI mode. The $\mathrm{CO}_{2}$ emission from diesel in HCCI mode is higher than from biodiesel in conventional mode (Shi et al., 2006).

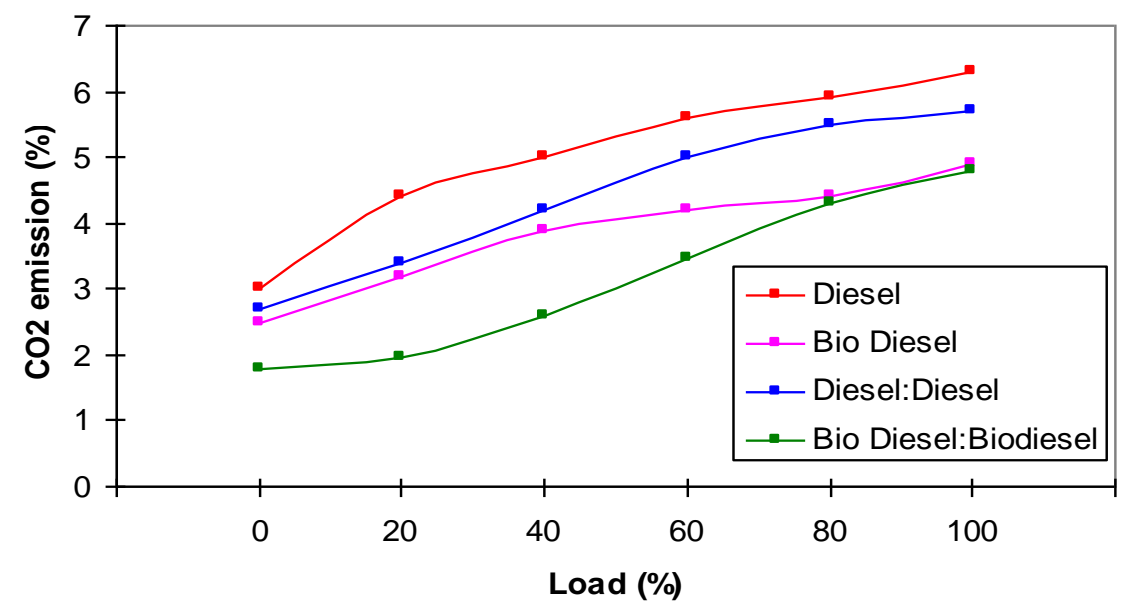

Figure 13. Comparison of $\mathrm{CO}_{2}$ between conventional and $\mathrm{HCCI}$ methods

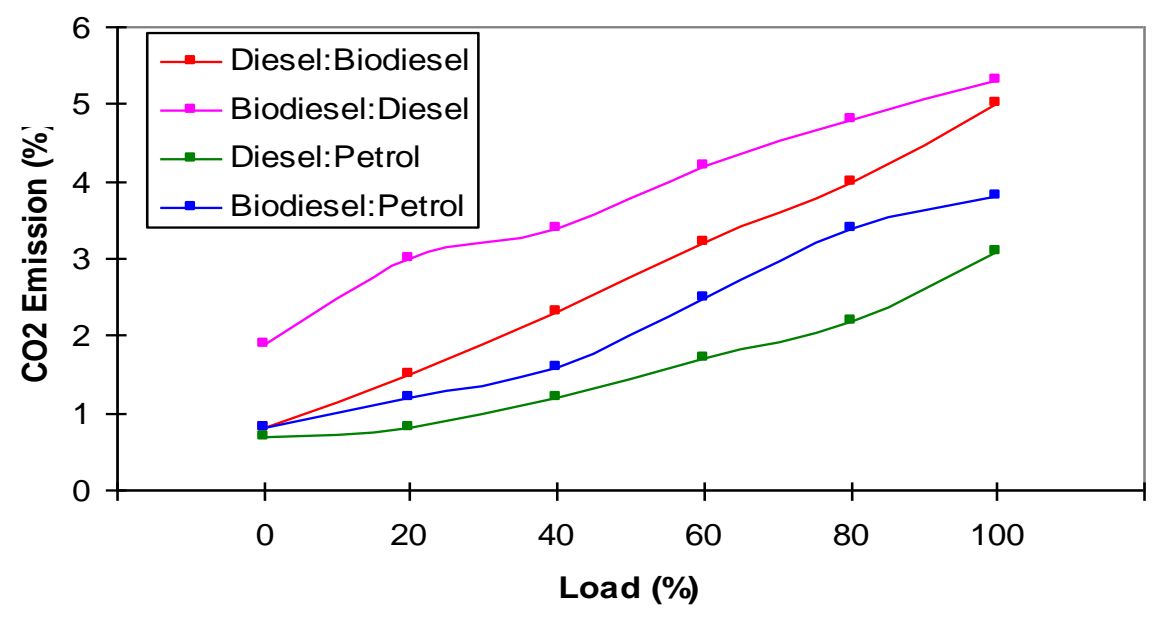

Figure 14. Comparison of $\mathrm{CO}_{2}$ emissions between different fuels in HCCI mode

\section{Effect of Load on Carbon Monoxide Emission}

The variation of $\mathrm{CO}$ emission with the variation of load for all the modes of operation in this study is represented in Figures 15 and 16. The study found that there is no variation of $\mathrm{CO}$ with the increase of load for all the HCCI modes of operation with different fuel as a primary and secondary fuel, except in the Diesel: petrol mode. In the case of conventional mode of operation, the $\mathrm{CO}$ emission initially increased with the increase of load, then further increasing of the load decreased the $\mathrm{CO}$ emission. Among all the HCCI modes, the Biodiesel: Biodiesel mode produced a very low level of $\mathrm{CO}$ emission compared to other cases of the HCCI mode (Shi et al., 2006). 


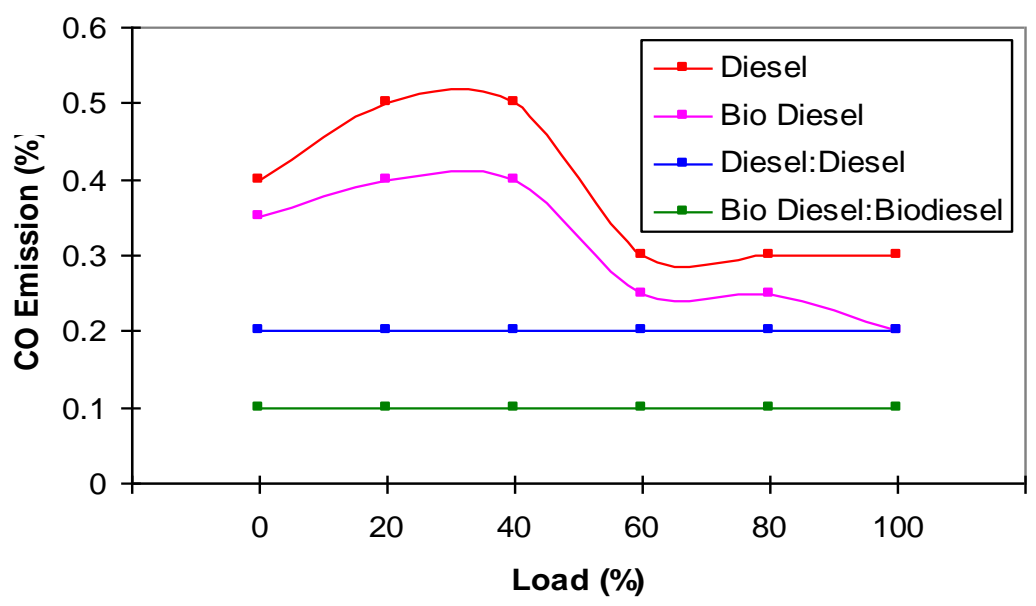

Figure 15. Comparison of CO emission between conventional and HCCI methods

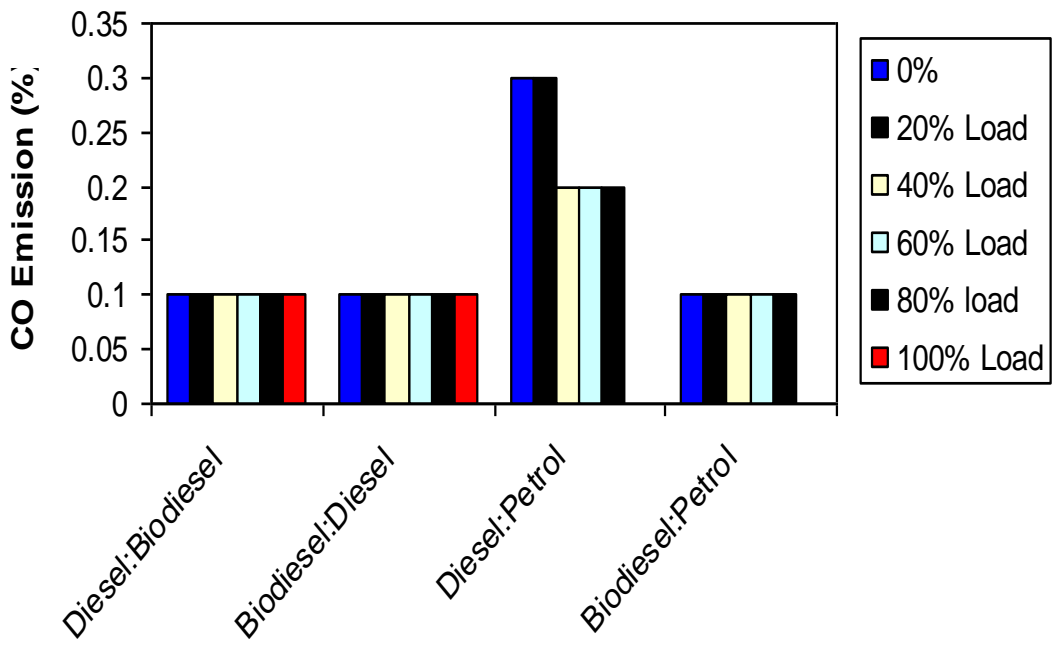

Fuel Combinations

Figure 16. Comparison of CO emission between different fuels in HCCI mode

\section{CONCLUSIONS}

The exhaust gas temperature from the HCCI mode is lower than the conventional mode of operation. Within the HCCI mode with different fuel combinations, biodiesel and petrol used as primary and secondary fuels respectively produced a lower temperature than the HCCI mode with other combinations of fuels. The study found that the HC emission decreased with the increase of load for the HCCI mode with all types of fuel. But in the case of the conventional mode, the $\mathrm{HC}$ emission increased with the increase of load. The lowest $\mathrm{HC}$ emission is observed for diesel and biodiesel as primary and secondary fuel respectively. Lower NOx emissions are observed for all the HCCI modes of operation compared to the conventional mode. Of all the HCCI modes of operation, diesel and petrol as primary and secondary fuel produced the lowest NOx emission. The study concludes that the emission from the HCCI mode is lower than the conventional mode, but the specific fuel consumption varied with different combinations of fuel in 
the HCCI mode. Diesel and petrol as primary and secondary fuel produce better results than the other fuel combinations, in terms of both the environment and fuel consumption.

\section{ACKNOWLEDGEMENTS}

This work is being supported by the Dr. M.G.R. Educational and Research Institute and Velammal Engineering College of Chennai. The Dr. M.G.R. Educational and Research Institute research project number is ME05 D001.

\section{REFERENCES}

Babajimopoulos, A., Assanis, D. and Fiveland, S. 2002. An approach for modeling the effects of gas exchange processes on HCCI combustion and its application in evaluating variable valve timing control strategies. SAE 2002-01-2829.

Gray, A.W. and Ryan, T.W. 1997. Homogeneous charge compression ignition (HCCI) of diesel fuel. SAE 971676.

Jiang, H., Wang, J. and Shuai, S. 2005. Visualization and performance analysis of gasoline homogeneous charge induced ignition by diesel. SAE 2005-01-0136.

Kim, D.S. and Lee, C.S. 2006. Improved emission characteristics of HCCI engine by various premixed fuels and cooled EGR. Fuel, 85: 695-704.

Shi, L., Cui, Y., Deng, K., Peng, H. and Chen, Y. 2006. Study of low emission homogeneous charge compression ignition (HCCI) engine using combined internal and external exhaust gas recirculation (EGR). Energy, 31: 2665-2676.

Standing, R., Kalian, N., Ma, T., Zhao, H., Wirth, M. and Schamel, A. 2005. Effects of injection timing and valve timings on CAI operation in a multi-cylinder DI gasoline engine. SAE Paper No. 2005-01-0132.

Yap, D., Karlovsky, J., Megaritis, A., Wyszynski, M. and Xu, H. 2005. An investigation into propane homogeneous charge compression ignition engine operation with residual gas trapping. Fuel, 84(18): 2372-2379.

Yeom, K., Jang, J. and Bae, C. 2006. Homogeneous charge compression ignition of LPG and gasoline using variable valve timing in an engine. Fuel, 86(4): 494-503.

Zhao, F., Asmus, T., Assanis, D., Dec, J., Eng, J. and Najit, P. 2003. Homogeneous charge compression ignition (HCCI) engine. Key Research and Development Issues, SAE SP-94.

\section{Nomenclature}

HC 1 Hydrocarbon emission from conventional mode combustion, ppm

HC 2 Hydrocarbon emission from PCCI-DI mode combustion, ppm

NO 1 Oxides of nitrogen emission from conventional mode combustion, ppm

NO 2 Oxides of nitrogen emission from PCCI-DI mode combustion, ppm

CO 1 Carbon monoxide emission from conventional mode combustion, \%

CO 2 Carbon monoxide emission from PCCI-DI mode combustion, \%

$\mathrm{CO}_{2} 1$ Carbon dioxide emission from conventional mode combustion, $\%$

$\mathrm{CO}_{2} 2$ Carbon dioxide emission from PCCI-DI mode combustion, \% 